\title{
Identify User's Satisfaction from Platform Using Behavior
}

\author{
L.H. Kuo ${ }^{1}$, W.H. Chen ${ }^{2, a}$, \& H.J. Yang ${ }^{1}$ \\ ${ }^{1}$ National Kaohsiung Normal University, Taiwan, R.O.C. \\ ${ }^{2}$ Taipei College of Maritime Technology, Taiwan, R.O.C.
}

\begin{abstract}
The purpose of this study was to verify a model of user's satisfaction of an e-learning environment based upon platform using behaviors. This is a non-experimental study. The data was collected from system management logs and users satisfaction survey after learning service. Total 314 users were invited in this study. First, theory model was identified. Second, the satisfaction survey results were prepared. Third, the behavior data of each survey subject were prepared. A CFA procedure were conducted to verify whether the data fits into the model. The model fit is positive with $\chi 2=2.06$, $\mathrm{p}$-value $=.151, \mathrm{df}=1, \mathrm{RMSEA}=.058$. The proposed two-factor theory model with simple structure fit the data. The love e-learning and satisfaction of e-learning factors are significantly supporting the hypothesis of a relationship between the factors. The findings suggested that identifying satisfaction from behavior is possible.
\end{abstract}

\section{Introduction}

\subsection{E-learning Platform}

E-learning is becoming an increasingly large part of higher education (Anderson, 2014, Duck and Parente, 2014, Kim, 2011).

Over 7.1 million college and university students took at least one online course by the end of the fall 2012 semester in the United States (Allen and Seaman, 2014). More than $71 \%$ of US colleges and universities offered online courses in 2012(Allen and Seaman, 2013) and onethird of higher education students took at least one online course in 2012 (Allen and Seaman, 2014).

\subsection{Problem Statement}

For managing an information system, there is always a need to understand user's behavior on system service. In an open learning environment, how can an information service provider keeping their users on using service is an important problem.

The purpose of this study was to identify whether an open ceremony affects on-line learning platform account keeping behavior.

\section{Literature review}

\subsection{Massive Open Online Courses}

According to the U.S. Department of Education Distance Learning Report (Bakia et al., 2012), the benefits of elearning are: a) to broaden access to the educational resources, b) to personalize learning, c) to provide flexibility in time and location for students, and d) to reduce school-based facilities' costs. However, the benefits of e-learning also bring some challenges into the field of education.

First, the retention rates in e-learning courses are 10$25 \%$ less than those for traditional face-to-face classes(Ali and Leeds, 2009, Angelina et al., 2007, Lee and Choi, 2013 ) in higher education. In other words, over one half of distance students may dropout of their education as a result of online courses (Duck and Parente, 2014). Second, students who take online courses for the first time tend to feel lonely and socially isolated not only because previously, tend to focus more on computer or Internet skills, technology accessibility, and general learner characteristics such as attitude toward online education or personal learning preferences (Bernard et al., 2004).

E-learning has been described as technology-based learning (Ali and Leeds, 2009, Kim, 2011), web-based learning (Bakia et al., 2012), network- and computerbased learning (Angelina et al., 2007), or "instructional environments supported by the Internet" (Bakia et al., 2012). Although each researcher uses different terms to describe the phenomenon of e-learning, the common element in all of the research is that learners need to be

\footnotetext{
${ }^{a}$ Corresponding author: aska1205@gmail.com
} 
familiar with using computer technology and the Internet to take online courses.

\section{Methodology}

\subsection{Model Hypotheses}

Structural equation modeling (SEM) is a collection of statistical techniques that allow a set of relationships between one or more IVs, either continuous or discrete, and one or more DVs, either continuous or discrete, to be examined. Both IVs and DVs can be either factors or measured variables. Structural equation modeling is also referred to as causal modeling, causal analysis, simultaneous equation modeling, analysis of covariance structures, path analysis, or confirmatory factor analysis (CFA). The latter two are actually special types of SEM.

One interesting feature of the analysis is that survival time (the DV) often is unknown for a number of cases at the conclusion of the study. Some of the cases are still in the study but have not yet failed: some employees have not yet left, some components are still functioning, some patients are still apparently well, or some patients are still living. For other cases, the outcome is simply unknown because they have withdrawn from the study or are for some reason lost to follow-up. Cases whose DV valuessurvival time - are unknown for whatever reason are referred to as censored.

SEM allows questions to be answered that involve multiple regression analyses of factors. Several conventions are used in developing SEM diagrams. Measured variables, also called observed variables, indicators, or manifest variables, are represented by squares or rectangles.

Factors have two or more indicators and are also called latent variables, constructs, or unobserved variables. Factors are represented by circles or ovals in path diagrams. Relationships between variables are indicated by lines; lack of a line connecting variables implies that no direct relationship has been hypothesized. Lines have either one or two arrows. A line with one arrow represents a hypothesized direct relationship between two variables, and the variable with the arrow pointing to it is the DV. A line with an arrow at both ends indicates an unanalyzed relationship, simply a covariance between the two variables with no implied direction of effect.

Parameters (path coefficients, variances, and covariances of IVs) are estimated to create an estimated population covariance matrix. If the model is good, the parameter estimates will produce an estimated matrix that is close to the sample covariance matrix. "Closeness" is evaluated primarily with the chi- square test statistic and fit indices.

\subsection{Covariance Algebra}

Within the family of survival- analysis techniques, different procedures are used depending on the nature of the data and the kinds of questions that are of greatest interest.

The idea behind SEM is that the hypothesized model has a set of underlying parameters which correspond to (1) the regression coefficients, and (2) the variances and covariances of the independent variables in the model (Bentler, 1995). These parameters are estimated from the sample data to be a "best guess" about population values. The estimated parameters are then combined by means of covariance algebra to produce an estimated population covariance matrix. This estimated population covariance matrix is compared with the sample covariance matrix and, ideally, the difference is very small and not statistically significant.

Covariance algebra is a helpful tool in calculating variances and covariances in SEM models; however, matrix methods are generally employed because covariance algebra becomes extremely tedious as models become increasingly complex. Covariance algebra is useful to demonstrate how parameter estimates are combined to produce an estimated population covariance matrix for a small example.

The three basic rules in covariance algebra appear below where $\mathrm{c}$ is a constant and $\mathrm{Xi}$ is a random variable:

$$
\begin{aligned}
& \text { 1. } \operatorname{COV}(\mathrm{c}, \mathrm{X} 1)=0 \\
& \text { 2. } \operatorname{COV}(\mathrm{cX} 1, \mathrm{X} 2)=\mathrm{cOVV}(\mathrm{X} 1, \mathrm{X} 2) \\
& \text { 3. } \operatorname{COV}(\mathrm{X} 1+\mathrm{X} 2, \mathrm{X} 3)=\operatorname{COV}(\mathrm{X} 1, \mathrm{X} 3)+\operatorname{COV}(\mathrm{X} 2, \mathrm{X} 3)
\end{aligned}
$$

In SEM, as in multiple regression, we assume that the residuals do not correlate with each other or with other variables in the models. In this model, both degree of motivation (Y1) and exam score (Y2) are DVs. Recall that a DV in SEM is any variable with a single- headed arrow pointing toward it. Treatment group (X1) with no singleheaded arrows pointing to it is an IV. To specify the model, a separate equation is written for each DV.

\subsection{Model Hypotheses}

The data set contains four continuous measured variables:

Hours, the number of a participant has learning on-line. Course, the number of a participant has taken from the e-learning service.

Plat.Sa, a Likert scale measure of degree of the satisfaction of the platform.

Cou.Sa, a Likert scale measure of degree of the satisfaction of the course.

The hypothesized model for these data is diagrammed in Figure 1. Latent variables are represented with oval and measured variables are represented with squares. A line with an arrow indicates a hypothesized direct relationship between the variables. 


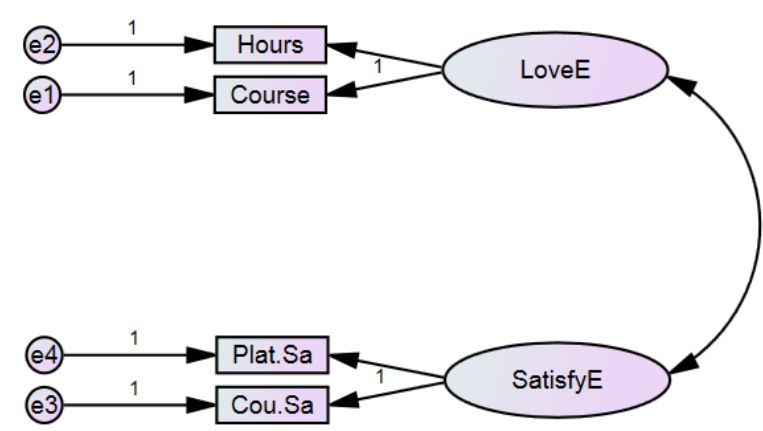

Figure 1. Hypothesized model for the study

\section{Findings}

In this session, the findings would be reported in descriptive statistics, CFA model, estimates of CFA model, and model fits summary.

For the model fits summary, three sets of model fit index are reported. Those are CMIN, RMSEA, and RMR \& GFI.

\subsection{Descriptive Statistics}

In Table 1., the descriptive statistics of variables were listed. The mean value of course is 9.22 . The mean value of hours is 19.45 .

The mean course satisfaction is 4.49 . The mean platform satisfaction is 4.51 . The sample number is 314 .

Table 1. N, Minimum, Maximum, Mean, \& Std. Deviation of Variables

\begin{tabular}{lrrrrrr}
\hline \multicolumn{5}{c}{ Descriptive Statistics } \\
\hline & $\mathrm{N}$ & Minimum & Maximum & Mean & $\begin{array}{c}\text { Std. Devia- } \\
\text { tion }\end{array}$ \\
\hline course_num & 31 & 6 & 10 & 9.22 & .869 \\
\hline hours & 4 & 31 & 12 & 22 & 19.45 & 2.853 \\
\hline CourseSa & 31 & 3 & 5 & 4.49 & .599 \\
\hline PlatformSa & 31 & 3 & 5 & 4.51 & .636 \\
\hline $\begin{array}{l}\text { Valid N (list- } \\
\text { wise) }\end{array}$ & 31 & 4 & & & & \\
\hline
\end{tabular}

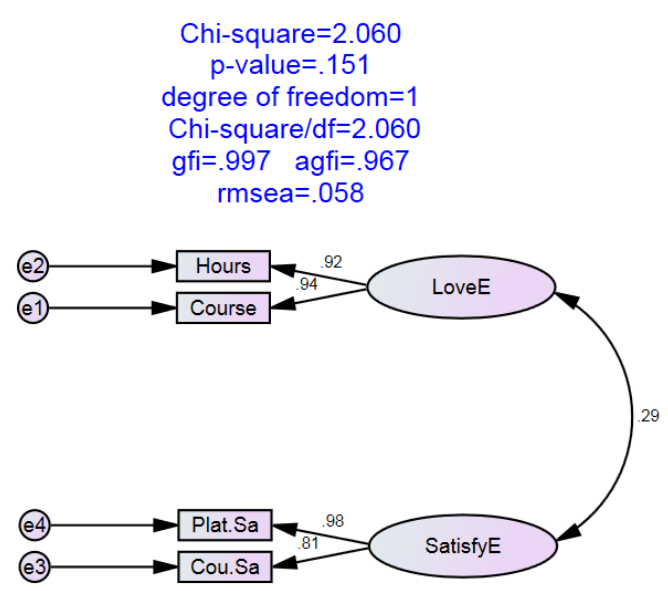

Figure 2. CFA Model of this study
All variables in the model are listed here, classified as either observed or unobserved, and as either endogenous or exogenous. A summary table shows the number of variables in each category, as well as the total number of variables in the model.

In Table 2, parameters of the proposed model were listed. This table shows the numbers of model parameters that fall into various categories.

The columns of the table are:

- Weights: regression weights

- Covariances: self explanatory

- Variances: self explanatory

- Means: self explanatory

- Intercepts: self explanatory

The rows of the table are:

- Fixed: parameters whose values are fixed at a constant value

- Labeled: parameters that are labeled

- Unlabeled: parameters that are neither fixed nor labeled. Such parameters are free to take on any value. (Labeled parameters can also be free -- a parameter that has been associated with a unique label is free to take on any value.)

Table 2. Parameter Summary

\begin{tabular}{|c|c|c|c|c|c|c|}
\hline & Weights & Covariances & Variances & ans & pts & otal \\
\hline Fixed & 6 & 0 & 0 & 0 & 0 & 6 \\
\hline Labeled & 0 & 0 & 0 & 0 & 0 & 0 \\
\hline Unlabeled & 2 & 1 & 6 & 0 & 0 & 9 \\
\hline Total & 8 & 1 & 6 & 0 & 0 & 15 \\
\hline
\end{tabular}

\subsection{CFA model}

The first hypothesis, that the model fits the data, has been evaluated and supported. The model fit is positive with $\chi 2=2.06, \mathrm{p}$-value $=.151, \mathrm{df}=1, \mathrm{RMSEA}=.058$. The proposed two-factor theory model with simple structure fit the data.

\subsection{Estimates of CFA Model}

Estimates of the following model parameters:

- Regression weights

- Variances of exogenous variables

- Covariances among exogenous variables

- Means of exogenous variables

- Intercepts for predicting endogenous variables

Estimates of the following quantities also appear here when requested.

- Squared multiple correlations

- Correlations among the exogenous variables

- Standardized regression weights 
In Table 3, the regression weights were listed and all indicators are significant.

Table 3. Regression weights

\begin{tabular}{lrrrrr}
\hline & & Estimate & S.E. & C.R. & P Label \\
\hline course_num $<---$ & LoveE & 1 & & \\
\hline hours & $<---$ & LoveE & 3.212 & 0.346 & $\begin{array}{r}9.28 \\
2 * * *\end{array}$ par_1 $^{*}$ \\
\hline CourseSa & $<---$ & SatisfyE & 1 & & \\
\hline PlatformSa & $<---$ & SatisfyE & 1.29 & 0.198 & $\begin{array}{r}6.51 \\
9 * *\end{array}{ }^{* *}$ par_2 \\
\hline
\end{tabular}
listed.

In Table 4 , the standardized regression weights were

Table 4. Standardized Regression Weights

\begin{tabular}{lllr}
\hline & & & Estimate \\
\hline course_num & $<---$ & LoveE & 0.945 \\
\hline hours & $<---$ & LoveE & 0.924 \\
\hline CourseSa & $<---$ & SatisfyE & 0.807 \\
\hline PlatformSa & $<---$ & SatisfyE & 0.982 \\
\hline
\end{tabular}

In Table 5, the covariance between two factors was listed.

Table 5. Covariances of Model

\begin{tabular}{|c|c|c|c|c|c|c|c|}
\hline & & & Estimate & S.E. & C.R. & $P$ & Label \\
\hline LoveE & $<-->$ & SatisfyE & 0.114 & $\begin{array}{r}0.0 \\
3\end{array}$ & $\begin{array}{r}3.82 \\
6\end{array}$ & $* * *$ & par \\
\hline
\end{tabular}

\subsection{Model Fit Summary}

\subsubsection{CMIN}

In Table 6 , the model is fit since the $\mathrm{p}$ value $>.05$. The CMIN is 2.060. The CMON/DF is 2.06. The model is acceptable fit.

Table 6. Model Fit of CMIN

\begin{tabular}{llllll}
\hline Model & NPAR & CMIN & DF & P & CMIN/DF \\
\hline Default model & 9 & 2.060 & 1 & $\begin{array}{l}.15 \\
1\end{array}$ & 2.060 \\
\hline $\begin{array}{l}\text { Saturated mod- } \\
\text { el }\end{array}$ & 10 & .000 & 0 & & \\
\hline $\begin{array}{l}\text { Independence } \\
\text { model }\end{array}$ & 4 & 785.138 & 6 & $\begin{array}{l}.00 \\
0\end{array}$ & 130.856 \\
\hline
\end{tabular}

\subsubsection{RMSEA}

In Table 7, the RMSEA is .058. The value indicates close approximate fit.

Table 7. Model Fit of RMSEA

\begin{tabular}{lllll}
\hline Model & RMSEA & LO 90 & HI 90 & PCLOSE \\
\hline Default model & .058 & .000 & .174 & .301 \\
\hline Independence model & .644 & .606 & .683 & .000 \\
\hline
\end{tabular}

\subsubsection{RMR \& GFI}

In Table 8 , the RMR is 0.008 . The range of the RMR is calculated based upon the scales of each indicator. The SRMR of 0 indicates perfect fit. The GFI is 0.997 . The GFI value suggests a good fit model.

Table 8. Model Fit of RMR \& GFI

\begin{tabular}{lllll}
\hline Model & RMR & GFI & AGFI & PGFI \\
\hline Default model & 0.008 & 0.997 & 0.967 & 0.1 \\
\hline Saturated model & 0 & 1 & & \\
\hline $\begin{array}{l}\text { Independence } \\
\text { model }\end{array}$ & 0.716 & 0.552 & 0.253 & 0.331 \\
\hline
\end{tabular}

\section{Conclusions}

The purpose of this study was to verify a model of user's satisfaction of an e-learning environment based upon platform using behaviors. This is a non-experimental study.

The data was collected from system management logs and users satisfaction survey after learning service. Total 314 users were invited in this study. First, theory model was identified. Second, the satisfaction survey results were prepared. Third, the behavior data of each survey subject were prepared. A CFA procedure were conducted to verify whether the data fits into the model.

The model fit is positive with $\chi 2=2.06$, pvalue $=.151, \mathrm{df}=1, \mathrm{RMSEA}=.058$. The proposed twofactor theory model with simple structure fit the data. The love e-learning and satisfaction of e-learning factors are significantly supporting the hypothesis of a relationship between the factors. The findings suggested that identifying satisfaction from behavior is possible.

\section{References}

1. ALI, R. \& LEEDS, E. 2009. The Impact of Face-toFace Orientation on Online Retention: A Pilot Study. Online Journal of Distance Learning Administration, 12.

2. ALLEN, I. E. \& SEAMAN, J. 2013. Changing Course: Ten Years of Tracking Online

3. Education in the United States [Online]. Babson Survey Research Group and Quahog Research Group, LLC. . Available: http://www.onlinelearningsurvey.com/reports/chang ingcourse.pdf [Accessed June 10 2015].

4. ALLEN, I. E. \& SEAMAN, J. 2014. Grade Change: Tracking Online Education in the United States [Online]. Babson Survey Research Group and Quahog Research Group, LLC. Available: http://www.onlinelearningsurvey.com/reports/grade change.pdf [Accessed June 10 2015].

5. ANDERSON, P. K. 2014. University education as relational: The challenge of online studies. Contemporary PNG Studies: DWU Research Journal, 19, 14. 
6. ANGELINA, L. M., WILliAMS, F. K. \& NATVIG, D. 2007. Strategies to Engage Online Students and Reduce Attrition. Journal of educators online, 4, 12.

7. BAKIA, M., SHEAR, L., TOYAMA, Y. \& LASSETER, A. 2012. Understanding the Implications of Online Learning for Educational Productivity [Online]. Washington, DC: U.S. Department of Education, Office of Educational Technology.

Available: http://www.sri.com/sites/default/files/publications/i mplications-online-learning.pdf [Accessed June 10 2015].
8. BERNARD, R. M., BRAUER, A., ABRAMI, P. C. $\&$ SURKES, M. 2004. The development of a questionnaire for predicting online learning achievement. Distance Education, 25, 17.

9. DUCK, J. M. \& PARENTE, D. H. 2014. How Do We Get To Tomorrow? The Path to Online Learning. Developments in Business Simulation and Experiential Learning, 35, 2.

10. KIM, J. 2011. Developing an instrument to measure social presence in distance higher education. British Journal of Educational Technology, 42, 15.

11. LEE, Y. \& CHOI, J. 2013. A structural equation model of predictors of online learning retention. The Internet and Higher Education, 16, 7. 